\title{
The rise and fall of HMOs: an American health care revolution
}

Jan Gregoire Coombs

Madison, University of Wisconsin Press, 2005, $412 \mathrm{pp}$,

ISBN 0299202402

Avedis Donabedian, who created the conceptual framework for quality assessments of health services, was interviewed shortly before his death in November 1999. He described the health care problems that he had encountered during his battle with cancer that lasted nearly three decades. Jan Gregoire Coombs quotes Donabedian in his last interview on page 277 of her book as follows: I have tried to choose doctors who worked together reasonably well but there are areas where no one takes responsibility, where planning is weak, when I am left on my own (...) HMOs today are good at measuring costs but pay little attention to measuring effects. The failure to look at outcomes undercuts all the reasons that so many of us were interested in the prepaid group practice... These few words of Donabedian summarize the message in the book The Rise and Fall of HMOs: an American Health Care Revolution.

In order to convey this message, author Jan Gregoire Coombs combines two medical historical studies. Firstly, she carried out a case study of the history of a famous prepaid group practice: the Greater Marshfield Community Health Plan. For this study she had access to all files and archives of this Health Plan. Secondly, she conducted a historical study on the legislation and health politics surrounding Health Maintenance Organizations (HMOs). The American presidential policies of Nixon, Johnson, Clinton and Bush are all covered. Coombs used secondary sources in this study, for example, newspapers in which Donabedian was interviewed. The second study forms the background of the more detailed case study on the Greater Marshfield Community Health Plan. Both studies are integrated: each chapter tells us about Marshfield as well as about Washington.

The author, a medical historian, explains why HMOs (an early form of Managed Care) failed to improve the delivery of health care or to control health care costs in the U.S. This is done through the lens of a real-life case study of the Greater Marshfield Health Plan in rural Wisconsin. This authoritative volume could be a valuable asset to those working in health policy, health care management, and health services research. Both
American and non-American readers will appreciate its encyclopaedic scope and rich historical perspective, as well as the important lessons that can be learned.

The book emcompasses four periods: 1920-1970 (introduction and Chapter 1), the period after the $\mathrm{HMO}$ Legislation in 1973 until the beginning of the 1980s (Chapters 2-7), the eighties (Chapters 8-10) and the nineties through 2005 (Chapters 11-14). Coombs describes how, in the first period, idealistic and paternalistic doctors and insurers in the rural area of Marshfield merged a clinic and the necessary health insurance for it. They created a health plan which worked for the whole population; the doctors were on the pay roll as well as being co-owners of the plan. However, only the top management levels of the insurance company (Blue Cross) and the clinic cooperated: there was a strong personal relationship between the CEOs of both authorities. On lower organizational levels under the CEOs, both parties had numerous small conflicts about finance, registration and book-keeping.

During the second period the HMOs began to grow. The word HMO was invented by the Nixon Administration in 1972. This government saw the HMOs as the remedy for beating the explosion of health care costs that was taking place. A National Health Insurance scheme, as proposed by the Johnson Administration was only feasible for the elderly in the form of Medicare. However, the HMOs were a good alternative for employees of corporations. In Chapter 7, Coombs assesses the quality of services in 1979, when the HMOs were at their peak. She quotes a Federal Office report on HMOs which summarized 19 major studies, 25 reports and 69 quality variables, all using Donabedian's structure, process and outcomes measurements. Coombs says on p. 124: HMOs fared very well compared to fee-for-service care: nineteen reports ranked the general quality of HMO care as superior and six others found that the delivery systems were comparable. None found overall care offered by HMOs to be inferior.

It was during the third period that the fall of the HMOs began. Blue Cross left the Greater Marshfield Community Health Plan in the 1980s. A few years later, in 1994, it started a lawsuit against the Marshfield. The plan had too big a market share for its rural area and that was, in the eyes of Blue Cross, an anti trust case. 
The Marshfield Clinic won the lawsuit after a costly and stressfull period with much mass media attention. Coombs quotes Chief Judge Richard Posner of the Court of Appeals in her book (p. 181): If an entire county has only twelve physicians, one can hardly expect or want them to set up in competition with each other. (...) Only as party of a large and sophisticated medical enterprise such as the Marshfield Clinic can they practice modern medicine in rural Wisconsin. Everywhere, insurers withdrew as owners of health plans. Employers purchased most of the nation's private health insurances and their selection criteria seldom gave priority to quality of care but to the costs involved (p. 132). So, insurance companies followed the priorities of the employers. In Wisconsin, the Marshfield Clinic had problems with compromising the quality of care because of price competition. In the nineteen-eighties and nineties, the good old group practices of the fifties eroded and disolved into managed care organizations.

During the fourth period since 1990, many attempts and proposals by the government and by the Institute of Medicine were made on a national level to restore the old values of prepaid group practices and universal coverage. The Clinton Administration proposed several reforms in the early nineties, which would have extended health care services to all Americans, as Coombs describes in Chapter 11. The failure of Clinton's proposals marked the fifth time in sixty years that Congress refused to accept a presidential call for universal health care. Instead, congress made some piecemeal initiatives to improve health for the low income Americans.

The Greater Marshfield Community Health Plan survived. In September 2003, the system treatment facilities reported 1.8 million patient encounters, 695 million dollar revenues and 30 million dollar net earnings (p. 233). However, Coombs warns on page 237: Marshfield and other nonprofits need government funding far in excess of the benefits from tax exemption to provide effective community service. Increasing commercialism in the health care industry clearly robbed most nonprofits of their important roles in protecting community health. At the end of the book we see the quotation of Avedis Donabedian with which I started this review. Donabedian's last words in his interview are: Sooner or later we are going to have to develop a national health care plan. The design and implementation of such a plan will be an exciting task of the fairly near future, I believe. On the last page of her book (p. 291) Jan Gregoire Coombs speaks comparable words.

This book: The Rise and Fall of HMOs provides the European reader with a splendid insight of policymaking in a case study on a famous $\mathrm{HMO}$ and of $\mathrm{HMO}$ legislation in Washington. The studies are well documented and many suggestions are made for further reading. I have two problems with the book. Firstly, I myself would prefer separate reports of the case study on the Marshfield Plan and the secondary study of HMO legislation with a synthesis at the end. In this way, it would be easier to follow exactly from which study Coombs draws which conclusions. Secondly, in the last chapters I miss an analytical approach towards understanding thirty years of interaction between employers, governments, doctors, insurance companies and patients. Was each of these actors of equal importance in all the three decades Coombs describes? Nevertheless, the book gives a clear and detailed description of the history of HMOs. I would recommend all European health service researchers who would like to learn about HMOs, managed care and health care competition to read this book.

Guus Schrijvers Editor-in-chief of IJIC Head of Julius Centre University Medical Centre Utrecht 